\title{
Enriched environment ameliorates adult hippocampal neurogenesis deficits in Tcf4 haploinsufficient mice
}

\author{
Katharina Braun ${ }^{1}$, Benjamin M. Häberle ${ }^{1}$, Marie-Theres Wittmann ${ }^{2^{*}}$ and D. Chichung Lie ${ }^{\text {* }^{*}}$
}

\begin{abstract}
Background: Transcription factor 4 (TCF4) has been linked to human neurodevelopmental disorders such as intellectual disability, Pitt-Hopkins Syndrome (PTHS), autism, and schizophrenia. Recent work demonstrated that TCF4 participates in the control of a wide range of neurodevelopmental processes in mammalian nervous system development including neural precursor proliferation, timing of differentiation, migration, dendritogenesis and synapse formation. TCF4 is highly expressed in the adult hippocampal dentate gyrus - one of the few brain regions where neural stem / progenitor cells generate new functional neurons throughout life.

Results: We here investigated whether TCF4 haploinsufficiency, which in humans causes non-syndromic forms of intellectual disability and PTHS, affects adult hippocampal neurogenesis, a process that is essential for hippocampal plasticity in rodents and potentially in humans. Young adult Tcf4 heterozygote knockout mice showed a major reduction in the level of adult hippocampal neurogenesis, which was at least in part caused by lower stem/progenitor cell numbers and impaired maturation and survival of adult-generated neurons. Interestingly, housing in an enriched environment was sufficient to enhance maturation and survival of new neurons and to substantially augment neurogenesis levels in Tcf4 heterozygote knockout mice.

Conclusion: The present findings indicate that haploinsufficiency for the intellectual disability- and PTHS-linked transcription factor TCF4 not only affects embryonic neurodevelopment but impedes neurogenesis in the hippocampus of adult mice. These findings suggest that TCF4 haploinsufficiency may have a negative impact on hippocampal function throughout adulthood by impeding hippocampal neurogenesis.
\end{abstract}

Keywords: Tcf4, PTHS, Adult neurogenesis, Hippocampus, Intellectual disability, Enriched environment

\section{Introduction}

The transcription factor 4 (TCF4, Gene ID: 6925) forms together with its paralogues TCF3 and TCF12 the class I basic Helix-Loop-Helix (bHLH) subgroup of transcription factors [1]. TCF4 has received growing attention following the discovery that loss-of-function mutations and

\footnotetext{
*Correspondence: marie-theres.wittmann@fau.de; chi.lie@fau.de ${ }^{1}$ Institute of Biochemistry, Emil Fischer Center, Friedrich-AlexanderUniversität Erlangen-Nürnberg, 91054 Erlangen, Germany

${ }^{2}$ Institute of Human Genetics, Universitätsklinikum Erlangen, Friedrich-

Alexander-Universität Erlangen-Nürnberg, 91054 Erlangen, Germany
}

single nucleotide polymorphisms are linked to neuropsychiatric disease. In humans, the TCF4 gene consists of 20 exons, 18 of which are protein-coding. Heterozygote lossof-function mutations of TCF4 before exon 7 have been linked to non-specific intellectual disability [2-4], while heterozygote disrupting mutations after exon 9 have been causally linked to Pitt-Hopkins Syndrome (PTHS, MIM \#610954), a neurodevelopmental disorder characterized by distinctive facial features, moderate to severe intellectual disability, autistic behavior, intermittent breathing abnormalities, seizures [5-7]. Moreover, SNPs in 
non-coding regions of the TCF4 gene are associated with an increased risk of schizophrenia and autism [8-11].

TCF4 is broadly expressed throughout the developing human and murine cortex and hippocampus [12-14]. TCF4 has pleiotropic functions in neurodevelopment. In rodents, TCF4 controls proliferation of cortical precursor cells, balances precursor proliferation versus differentiation, regulates fate choices and migration, and modulates dendrite and spine development [14-18]. Loss of Tcf4 causes imbalanced generation of deep vs. upper layer neurons, delays neuronal differentiation, and impairs dendritogenesis and synapse formation $[14,17$, 19]. Development of the hippocampal formation appears to be particularly reliant on precise TCF4 dosage. MRanalyses uncovered small hippocampi in individuals with PTHS $[13,20]$. Heterozygote Tcf4 knockout mice show a significant reduction in hippocampal volume [13], while homozygote TCF4 knockout mice and transgenic mice with a homozygote embryonic neural stem cell specificdeletion of TCF4 show severe hippocampal hypoplasia $[12,17,19]$.

TCF4 is highly expressed in the adult brain [13], and is thought to have critical function in the regulation of neural plasticity [21-23]. High levels of TCF4 expression are observed in the dentate gyrus of the hippocampal formation [13]. The dentate gyrus is one of the few regions of the CNS, where neural stem cells give rise to new neurons throughout adulthood. Adult hippocampal neurogenesis has been unequivocally demonstrated in rodents and non-human primates [24]. Studies using different methodologies to detect adult-born neurons provided strong evidence for the existence of adult hippocampal neurogenesis in humans [25-27]. Nevertheless, the notion of adult neurogenesis in humans remains contested as a recent study failed to detect the expression of markers indicative of neurogenesis in the adult human hippocampus [28]. In rodents, adult hippocampal neurogenesis is critical for the regulation of anxiety and depression-like behaviour as well as for hippocampusdependent learning and memory [29]. Notably, impaired adult hippocampal neurogenesis was found to contribute to cognitive deficits in preclinical models for autismspectrum disorders and intellectual disability [30-33].

Here, we sought to determine whether Tcf4 haploinsufficiency, which has been associated with autism and intellectual disability in humans, affects adult hippocampal neurogenesis. Analysis of Tcf4 heterozygote knockout mice revealed that Tcf4 haploinsufficiency is associated with a smaller size of the hippocampal neural stem/progenitor cell pool and impaired maturation and survival of adult-born dentate granule neurons. Interestingly, long-term housing in an enriched environment enhanced survival of adult-born dentate granule neurons and substantially increased adult hippocampal neurogenesis levels, raising the interesting possibility that in mice behavioural modifications during adulthood can ameliorate a subset of neural deficits caused by TCF4 haploinsufficiency.

\section{Results \\ Tcf4 haploinsufficiency leads to proliferation deficits in adult neurogenesis}

We first performed immunohistochemical analysis against TCF4 and select stage-specific markers to confirm the notion that TCF4 is expressed in the adult hippocampal neurogenic lineage. Indeed, TCF4 co-localized with the radial glia like marker NESTIN (Fig. 1a), with MCM2, a marker for proliferating precursor cells (Fig. 1b), with DCX, a marker for immature neurons (Fig. 1c) and with CALBINDIN, a marker for mature granule cells (Fig. 1d), indicating that TCF4 is expressed during all stages of adult hippocampal neurogenesis. In line with the central function of TCF4 in hippocampal development and our previous report, Tcf4 haploinsufficient mice (Tcf$4 \mathrm{Het}$ ) showed a significantly reduced volume of dentate gyrus granule cell layer [Volume in $\mu^{3}$ : control $5.77 \times 10^{8} \pm 3.58 \times 10^{7} ; \quad$ Tcf 4 Het $4.51 \times 10^{8} \pm 2.41 \times 10^{7}$; p-value $=0.012$ (Fig. 2a)] [13].

Next, we investigated whether adult hippocampal neurogenesis is altered by Tcf4 haploinsufficiency. To assess the impact of Tcf4 haploinsufficiency on proliferation, young adult Tcf4Het and control mice were injected for three consecutive days with the thymidine analogue BrdU and sacrificed three hours after the final injection. Tcf 4 Het mice showed a significant decrease in the number of BrdU positive cells even following correction for the smaller dentate gyrus volume [BrdU + cells/ $\mu \mathrm{m}^{3}$ : control $2.44 \times 10^{-5} \pm 1.14 \times 10^{-6}$; Tcf 4 Het $1.93 \times 10^{-}$ ${ }^{5} \pm 1.79 \times 10^{-6} ; \quad \mathrm{p}$-value $=0.049 \quad$ (Fig. 2b) $]$, indicating that Tcf4 haploinsufficiency reduced proliferation. Tcf4 haploinsufficient mice showed a strong trend towards lower densities of radial glia-like stem/precursor cells $\left[\mathrm{NESTIN}+\right.$ cells $/ \mu \mathrm{m}^{3}$ : control $1.82 \times 10^{-5} \pm 1.94 \times 10^{-6}$; Tcf4Het $\quad 1.31 \times 10^{-5} \pm 1.35 \times 10^{-6} ; \quad \mathrm{p}$-value $=0.0570$ (Fig. 2c)]. The fraction of MCM2 + cells amongst the NESTIN + population, however, was comparable [NESTIN + MCM2 + / NTIN + cells in \%: control 24.71 \pm 1.81 ; Tcf 4 Het $27.50 \pm 2.62$; p-value $=0.4006$ (Fig. 2c)], suggesting that while $T c f 4$ haploinsufficiency resulted in a strong tendency towards lower numbers of radial glia-like stem/ precursor cells, it did not affect stem/precursor cell activation. Given that the reduction in cell proliferation was comparable to the reduction in the number of radial glia-like stem/precursor cells, it seems likely that the decreased proliferative activity in the adult neurogenic 
a
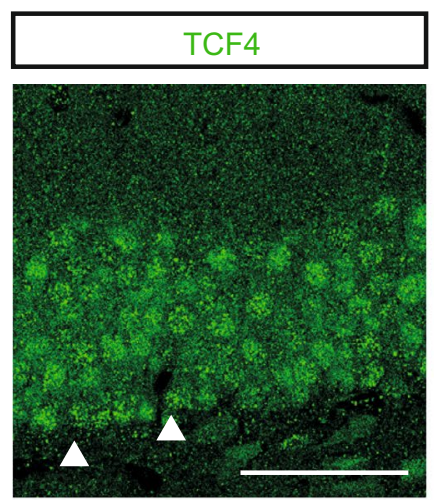

b
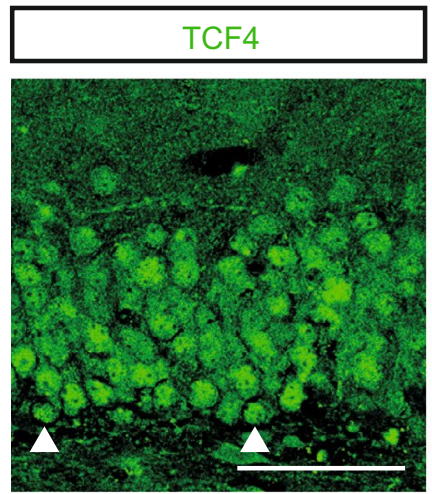

c
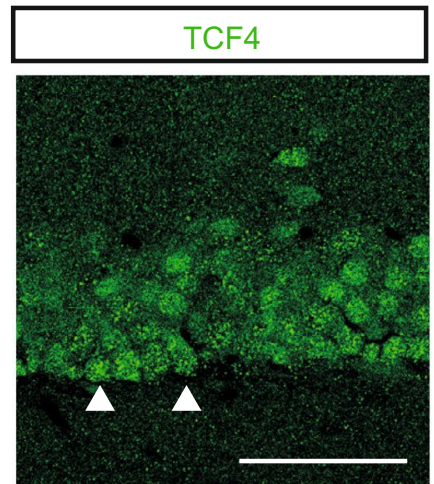

d
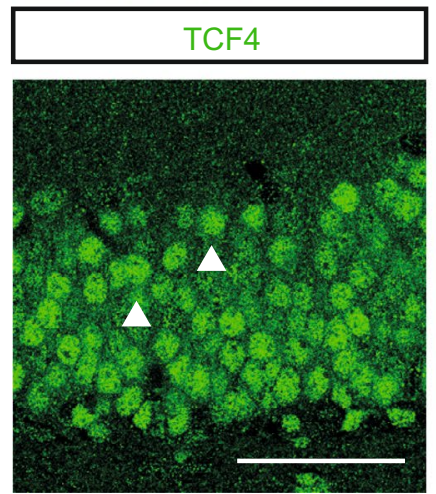
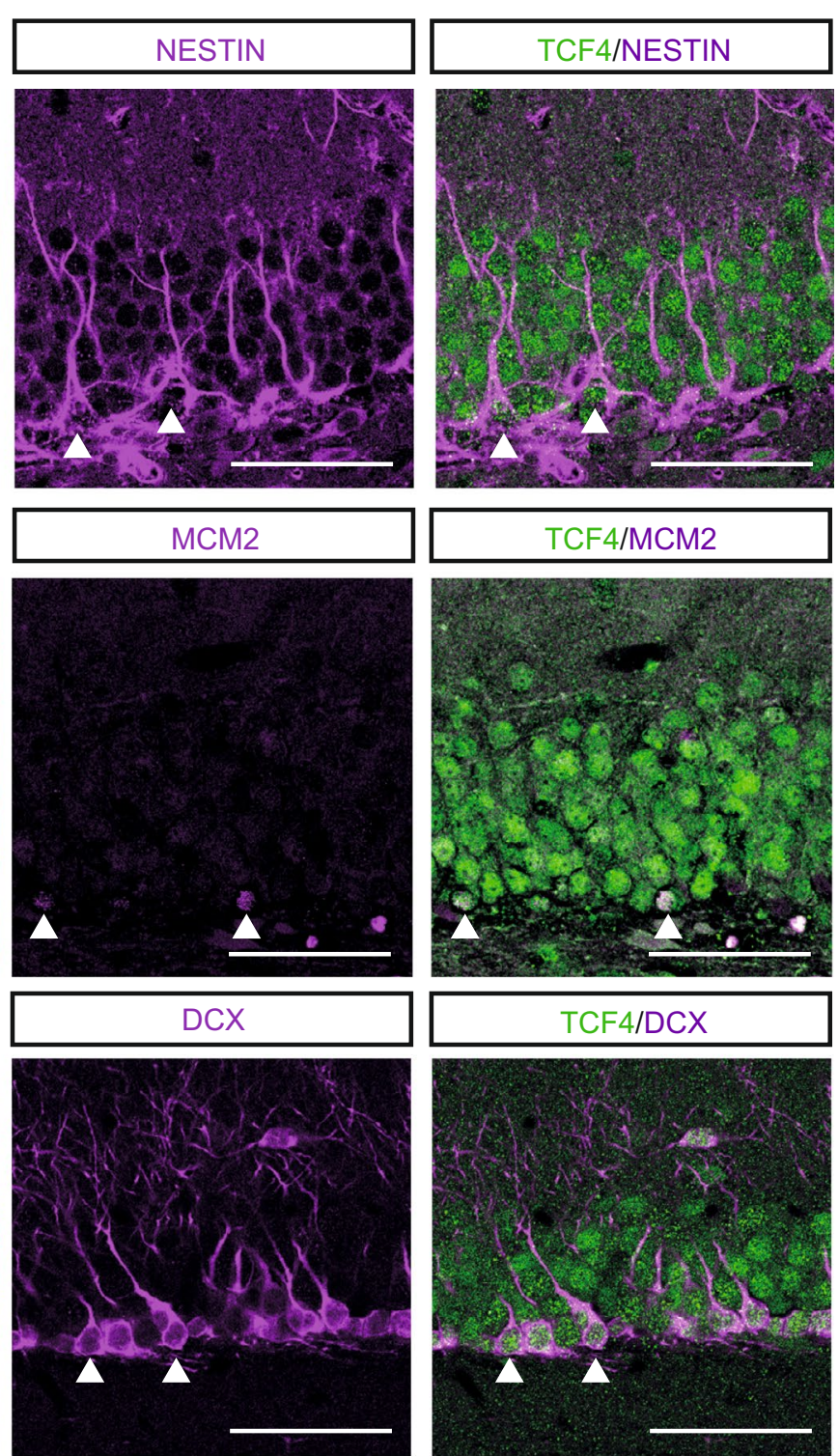

CALBINDIN
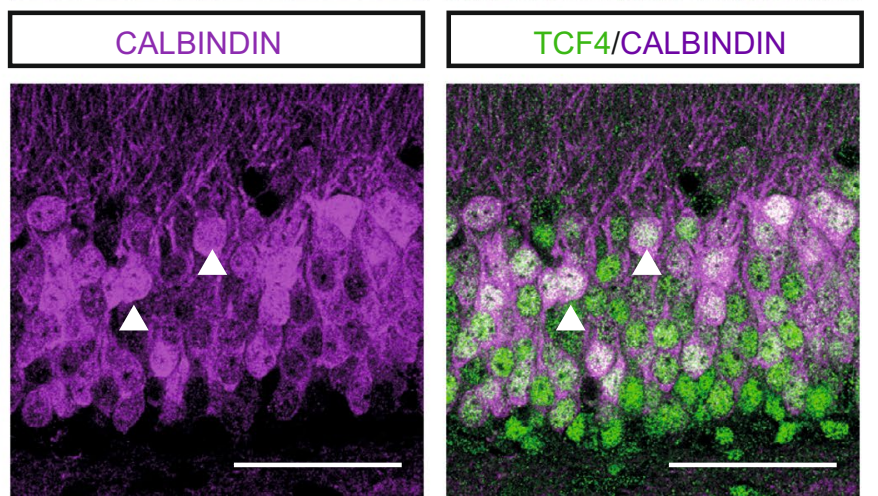

Fig. 1 TCF-4 is expressed at all stages of adult neurogenesis. Representative images of TCF-4 and NESTIN a, MCM2 b, DCX c and CALBINDIN d. NESTIN is a marker for aNSCS, MCM2 marks proliferative cells. DCX marks immature neurons and CALBINDIN is a marker for mature granule cell neurons. The triangles mark example cells with co-expression of TCF-4 with the respective marker. Scale bar, $50 \mu \mathrm{m}$ 
(See figure on next page.)

Fig. 2 Tcf4 haploinsufficiency leads to proliferation deficits in adult neurogenesis. a Representative images and quantification of the DG volume of control and Tcf4Het mice. Haploinsufficient mice show a reduced volume of the DG in comparison to control mice. Scale bar, $100 \mu \mathrm{m} ; \mathrm{n}=4 . \mathbf{b}$ Representative images and quantification of BrdU incorporating cells in the DG $3 \mathrm{~h}$ after last BrdU injection. Tcf4Het mice have a decreased number of BrdU + cells in DG. Scale bar, $100 \mu m ; n=6$. c Representative images and quantification of the number of aNSCs and their activation. Tcf4Het animals show a strong trend towards lower number of NESTIN + cells. The activation ratio is unaltered. Scale bar, $50 \mu m ; n=6$. Data are presented as mean \pm SEM

niche of Tcf4Het mice is to a significant extent caused by decreased radial glia-like stem/precursor cell numbers.

\section{Tcf4 haploinsufficiency impairs neuronal fate decision, differentiation and maturation in adult neurogenesis}

We next determined the number of BrdU positive cells four weeks after a three-day BrdU pulse. Tcf4 haploinsufficient mice showed a reduced number of BrdU incorporating cells in the DG of compared to control $\left[\mathrm{BrdU}+\mathrm{cells} / \mu \mathrm{m}^{3}\right.$ : control $1.07 \times 10^{-5} \pm 1.75 \times 10^{-6} ; \mathrm{Tcf}$ 4 Het $4.67 \times 10^{-6} \pm 3.96 \times 10^{-7}$; p-value $=0.011$ (Fig. 3a)] . The ratio of the number of BrdU + cells between the four week and three-hour time-point was strongly reduced in Tcf 4 Het mice [BrdU ratio in \%: control 43.93 \pm 7.63 ; Tcf 4 Het $24.25 \pm 2.3$; $\mathrm{p}$-value $=0.034$ (Fig. 3b)], indicating that Tcf4 haploinsufficiency impaired survival of newborn cells.

To evaluate the fate of surviving cells we co-stained BrdU with DCX and PROX1, markers for immature neurons and granule neurons, respectively. The fraction of $\mathrm{BrdU}+$ cells expressing a neuronal marker appeared to be slightly reduced in Tcf4Het mice. Interestingly, quantification of PROX1+/DCX + double positive cells (immature neurons) and of PROX1+/ DCX - cells (mature neurons) revealed a significant increase in the fraction of immature neurons [PROX1 +1 $\mathrm{DCX}+$ amongst BrdU + cells in \%: control 13.98 \pm 2.40 ; Tcf4Het 27.45 \pm 5.55 ; p-value $=0.034$ (Fig. 3c)] and a substantial decrease in the fraction of mature neurons $[$ BrdU + PROX1 + DCX- in \%: control 70.37 \pm 3.79 ; Tcf4 Het $46.17 \pm 8.54 ;$ p-value $=0.017$ (Fig. 3c)] amongst BrdU-labeled cells, suggesting that Tcf4 haploinsufficiency interfered with the generation of mature dentate granule neurons.

\section{Enriched environment ameliorates defects in adult neurogenesis due to Tcf4 haploinsufficiency}

Enriched environment (EE) is a powerful stimulant of adult hippocampal neurogenesis in adult wildtype mice [34-36]. We next sought to determine, whether EE can be harnessed to ameliorate neurogenesis deficits in Tcf4 haploinsufficient mice. To this end, we placed a cohort of Tcf $4 \mathrm{Het}$ mice-in parallel to the above described cohorts, which were kept under home cage conditions-in EE conditions (Tcf4Het EE). Similar to the other cohorts, animals received a 3-day pulse of BrdU. Analysis of the Tcf4Het EE cohort was performed four weeks after the final BrdU injection. Quantification of NESTIN + and MCM2 + cells indicated that EE did not affect radial glia-like cell numbers and their activation [NESTIN+cells $/ \mu \mathrm{m}^{3}:$ Tcf 4 Het $1.92 \times 10^{-5} \pm 2.51 \times 10^{-6}$; Tcf4Het EE $1.34 \times 10^{-5} \pm 1.43 \times 10^{-6} ; \quad$-value $=0.1013$ (Fig. 4a); NESTIN + MCM $2+/$ NESTIN + cells in \%: Tcf4Het 26.23 \pm 3.34 ; Tcf4 Het EE 22.13 \pm 2.11 ; $\mathrm{p}$-value $=0.1022$ (Fig. 4a)], and overall proliferation activity $\left[\mathrm{MCM} 2+\right.$ cells $/ \mu \mathrm{m}^{3}$ : Tcf 4 Het $3.83 \times 10^{-5} \pm 1.21 \times 10^{-}$ ${ }^{6}$; Tcf 4 Het EE $4.10 \times 10^{-5} \pm 3.81 \times 10^{-6}$; p-value $=0.523$ (Fig. 4a)].

Tcf4Het mice housed in an enriched environment, however, had a twofold increase in BrdU + cells compared to $T c f 4$ haploinsufficient mice housed in home cages (Tcf$4 \mathrm{Het})\left[\mathrm{BrdU}+\mathrm{cells} / \mu \mathrm{m}^{3}:\right.$ Tcf 4 Het $4.67 \times 10^{-6} \pm 4.43 \times 10^{-}$ ${ }^{7}$; Tcf4Het EE $9.88 \times 10^{-6} \pm 1.81 \times 10^{-6}$; p-value $=0.0232$ (Fig. 4d)]. Notably, EE decreased the fraction of PROX1 + /DCX + immature neurons [PROX1 + DCX + / BrdU + in \%: Tcf4Het 27.45 $\pm 5.55 ; \quad T c f 4$ Het $\mathrm{EE}$ $9.13 \pm 1.37 ; \mathrm{p}$-value $=0.020$ (Fig. 4e) $]$ and increased the fraction of PROX1+/DCX- mature granule neurons amongst BrdU labelled cells [BrdU+PROX1+DCXin \%: Tcf4Het $46.17 \pm 8.54$; Tcf4Het EE $77.74 \pm 3.68$; p-value $=0.0162$ (Fig. 4e)]. Collectively, these data indicate that long-term exposure to EE ameliorates survival and maturation deficits in adult hippocampal neurogenesis of Tcf4 haploinsufficient mice.

\section{Discussion}

Loss-of-function mutations in the bHLH transcription factor TCF4 are linked to neurodevelopmental disorders such as intellectual disability and Pitt-Hopkins Syndrome. Here, we analysed a Tcf4 heterozygote knockout mouse model to begin to shed light on the dependency of adult neurogenesis in the hippocampal dentate gyrus on Tcf4 gene dosage. Our analyses confirm that constitutive Tcf4 haploinsufficiency is associated with a reduced dentate gyrus size and reveal a profound reduction in the production of new dentate granule neurons during adulthood. We found that Tcf4 haploinsufficiency reduced the proliferative activity in the adult dentate gyrus. Given that Tcf 4 Het mice showed a 30\% reduction in radial-glia like stem / progenitor cells and that the reduction in proliferation (about 20\% 


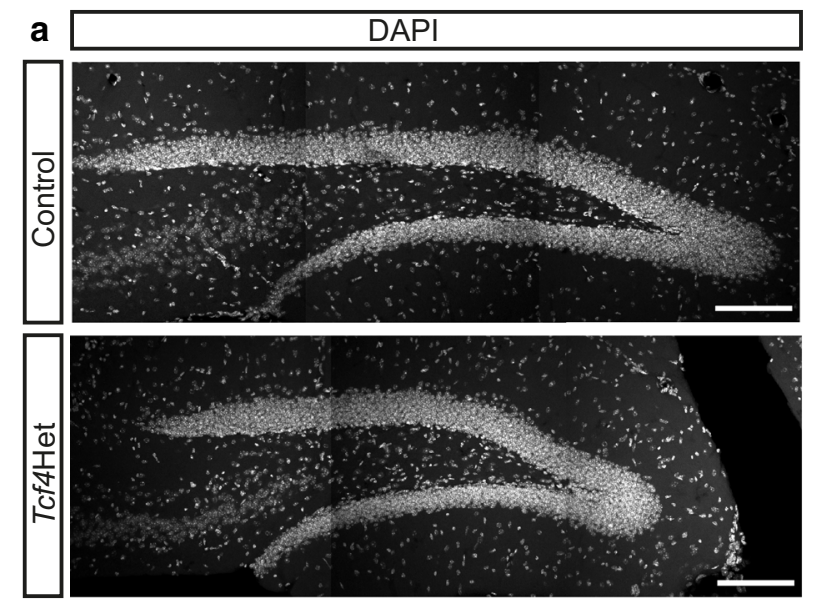

total DG volume
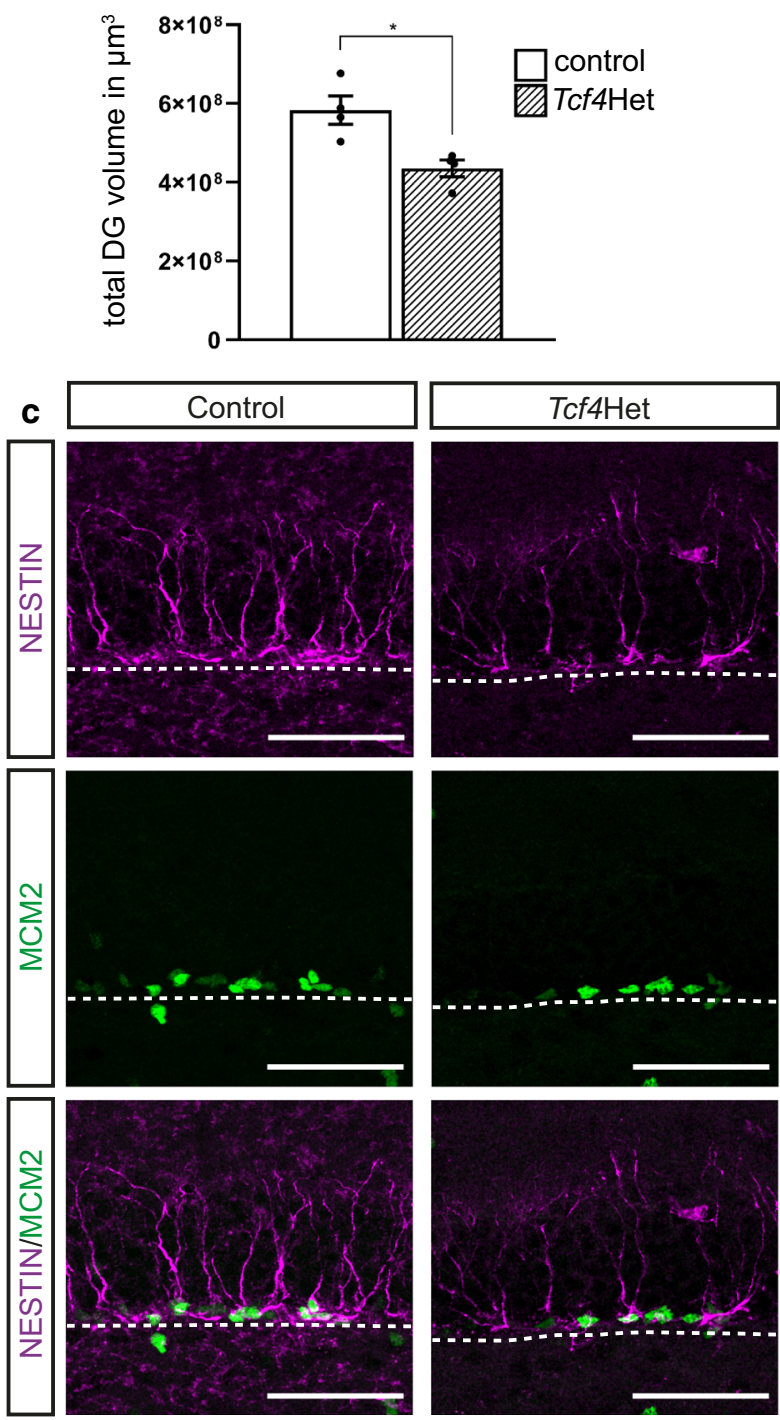

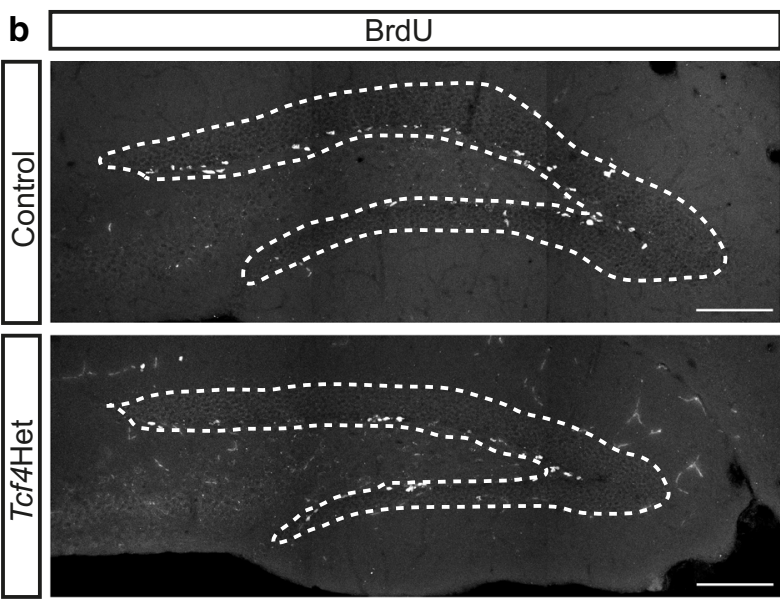

BrdU+ cells in the DG

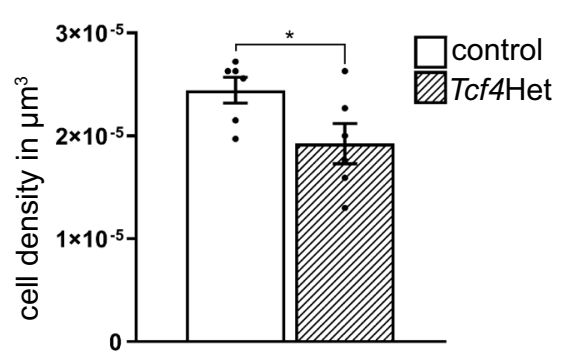

NESTIN+ cells in the DG

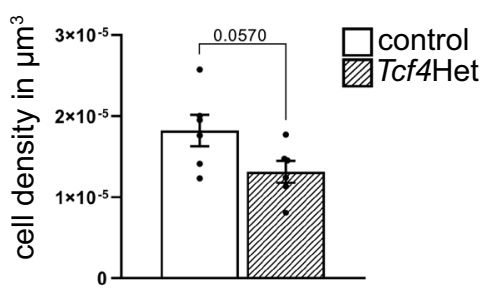

Activation ratio in \%

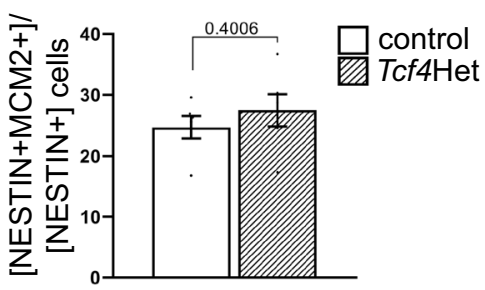




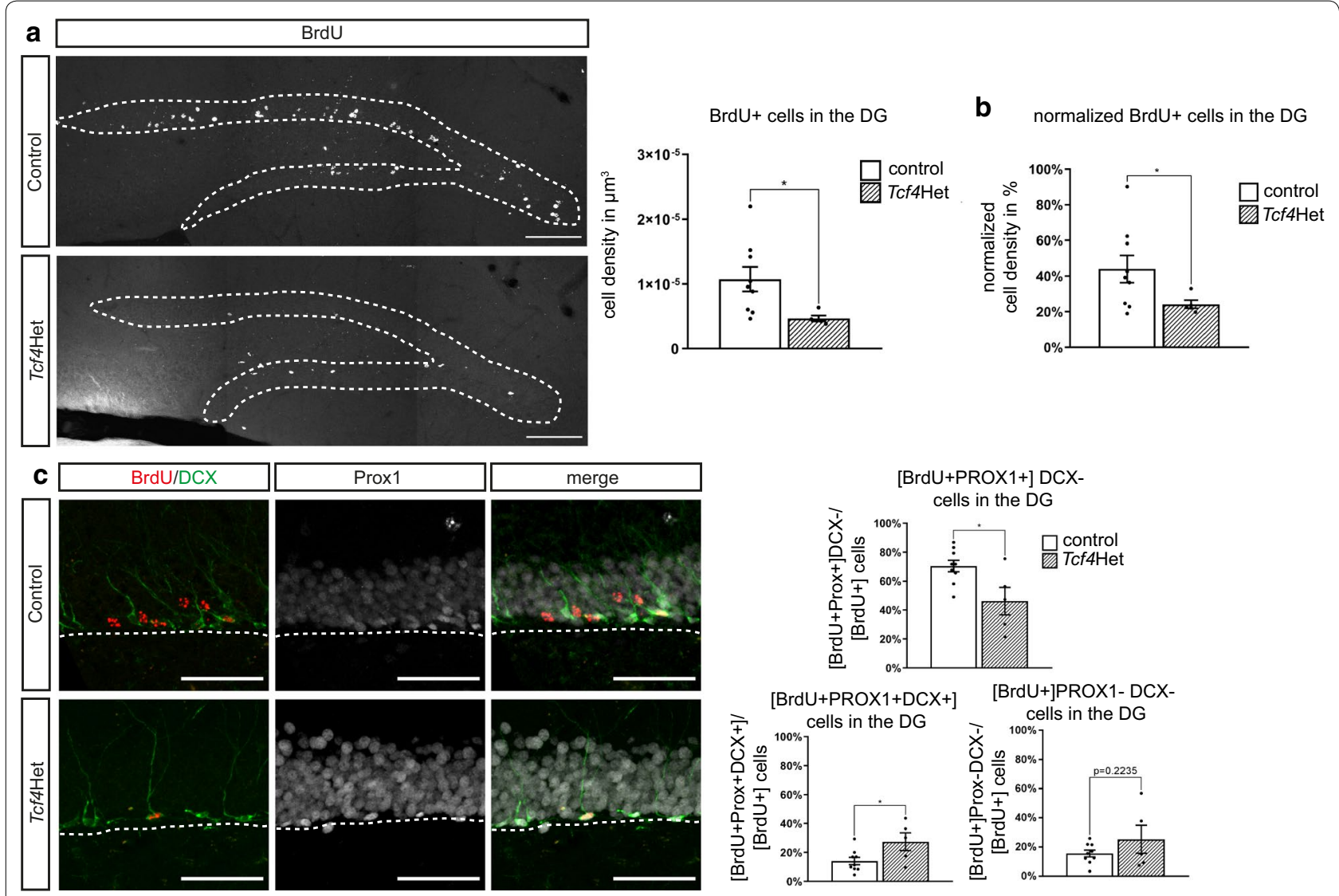

Fig. 3 Tcf4 haploinsufficiency impairs neuronal survival, differentiation and maturation in adult neurogenesis. a Representative images and quantification of BrdU incorporating cells in the DG four weeks after last BrdU injection. Tcf4Het mice have a decreased number of $\mathrm{BrdU}+$ cells in DG. Scale bar, $100 \mu \mathrm{m} ; \mathrm{n}=9$ and 5 . $\mathbf{b}$ Quantification of the percentage of surviving cells normalized to number of cells that were generated four weeks before. $\mathbf{c}$ Representative images and quantification of the number of $\mathrm{BrdU}+$ single, $\mathrm{BrdU}+\mathrm{DCX}+\mathrm{PROX} 1+$ triple and BrdU + PROX1 + double positive cells four weeks after last BrdU injection. PROX1 labels granule neurons and DCX immature neurons. The number of immature neurons (BrdU + DCX + PROX1 + triple positive) is increased in Tcf4Het animals, whereas the number of mature neurons (BrdU + PROX $1+$ positive) is reduced. Scale bar, $50 \mu m ; n=9$ and 5. Data are presented as mean \pm SEM

less BrdU incorporating cells) was in a comparable range, it seems most likely that the proliferation deficit was to a large part the consequence of a smaller radial-glia like stem / progenitor cell pool. It will be interesting to determine, why the Tcf4 haploinsufficient dentate gyrus harbours a smaller stem cell population. Radial-glia like stem / progenitor cells in the murine dentate gyrus are derived from neural precursor cells in the mouse dentate neuroepithelium, which migrate into the primitive dentate region and enter quiescence around postnatal day 7. TCF4 is highly expressed in the dentate neuroepithelium and the developing hippocampus $[12,13]$. Considering recent findings that TCF4 dosage affects proliferation of embryonic neural precursor cells [14-16] and cell migration in the developing CNS $[14,17]$ including the migration of hippocampal neural progenitors [12], it is tempting to speculate that a combination of proliferation and migration defects of neural precursors contribute to the decreased size of the neural stem/progenitor cell pool in the adult dentate gyrus. TCF4 and the related E-protein TCF3 inhibit neural stem cell differentiation and cell cycle exit in the adult subventricular zone [37] raising the alternative possibility that Tcf4 haploinsufficiency results in accelerated stem cell depletion due to premature neuronal fate commitment.

Tcf4 haploinsufficiency had a profound impact on survival of adult generated cells. It is possible that TCF4 directly regulates the expression of, e.g., anti-apoptotic pathways in the adult neurogenic lineage. Adult-born neuron survival is highly dependent on maturation and synaptic integration [38-40]. Recent studies reported that loss-of-Tcf4 causes delayed maturation of embryonically and early postnatally born neurons, impairs dendrite and synapse formation in the developing cortex [17, 41], and decreases spine density of mature cortical and hippocampal neurons [42]. When analysing the marker profile of 4-week old adult-born neurons, we found that 


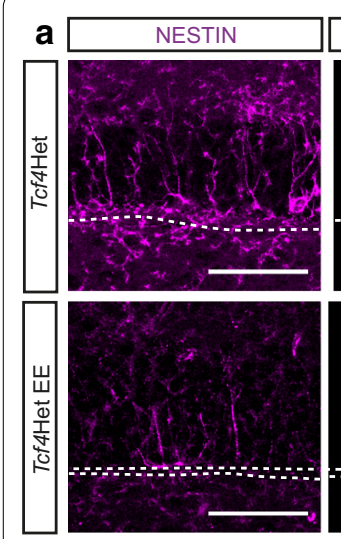

NESTIN+ cells in the DG

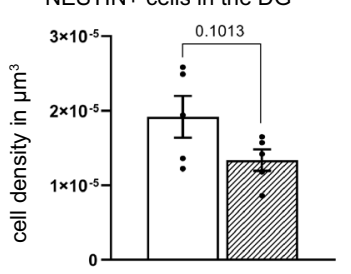

b
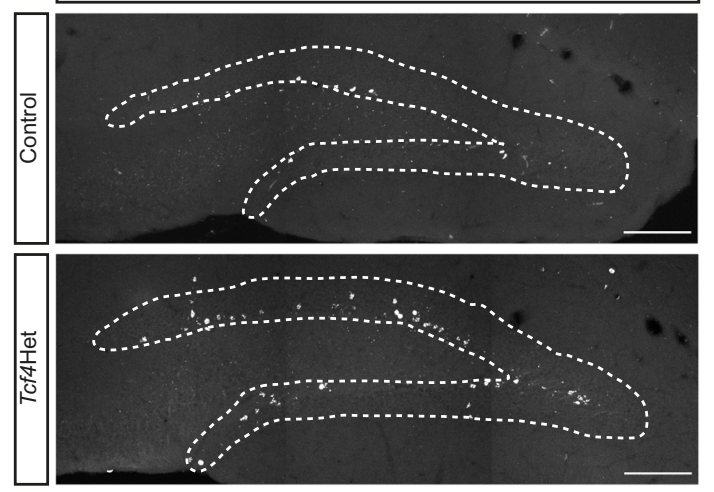

BrdU+ cells in the DG
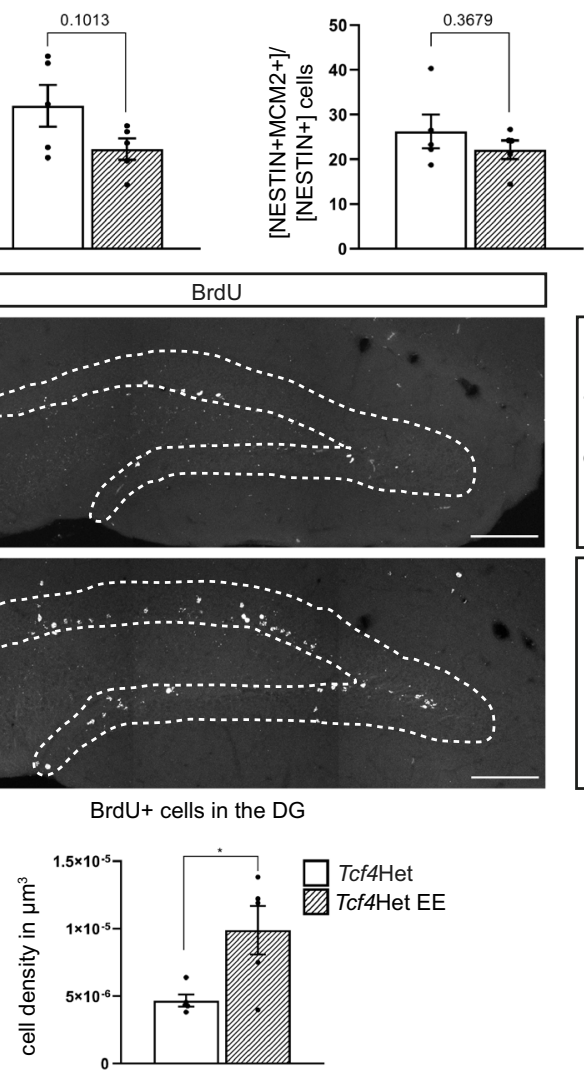

NESTIN/MCM2
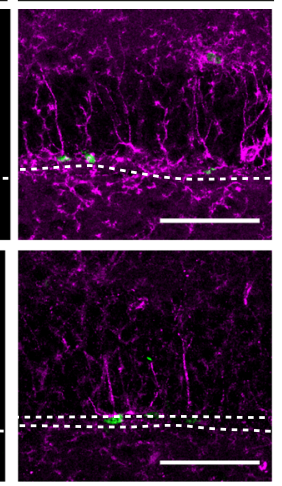

Activation ratio in \%
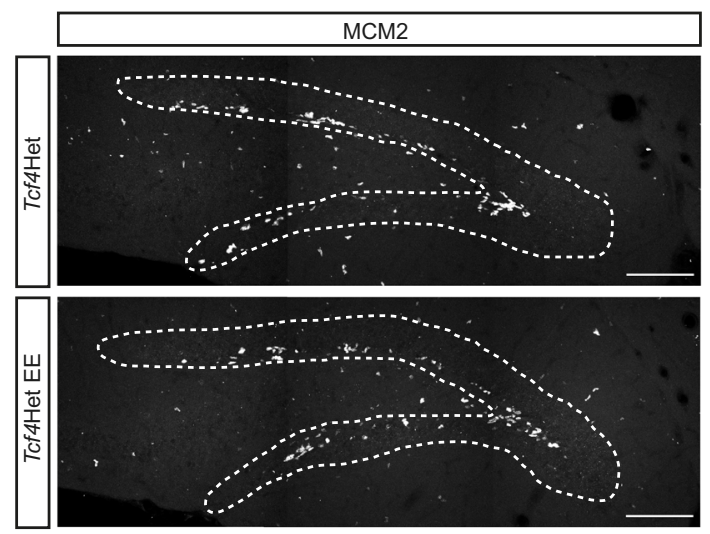

$\mathrm{MCM} 2+$ cells in the DG

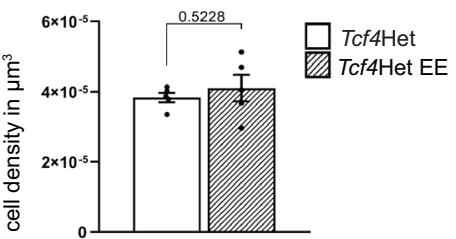

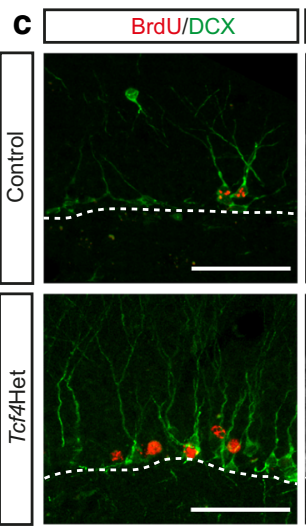

[BrdU+]PROX1- DCXcells in the DG

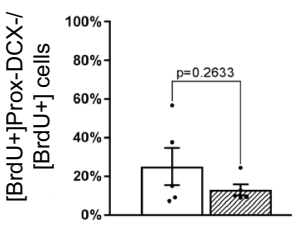

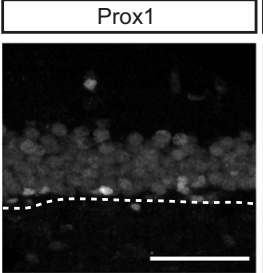

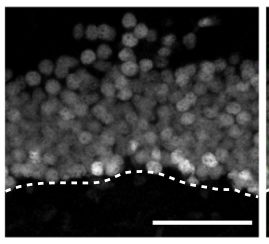

[BrdU+PROX1+] DCX cells in the DG

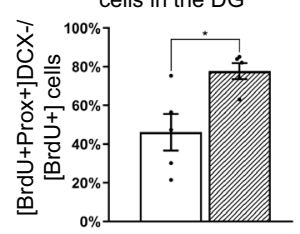

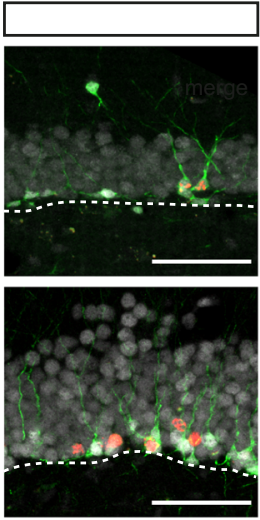

[BrdU+PROX1+DCX+] cells in the DG

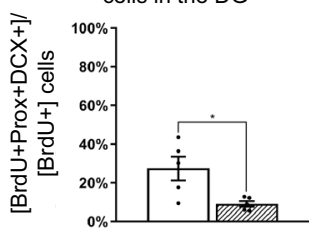

Fig. 4 Enriched environment ameliorates defects in adult neurogenesis due to Tcf4 haploinsufficiency. a Representative images and quantification of the number of proliferative cells, NESTIN + (aNSCs) and the activation of aNSCs in the DG after five weeks of EE. The number of proliferative cells, aNSCs and the activation ratio of aNSC is unaltered. Scale bar, $50 \mu \mathrm{m} ; n=5$. b Representative images and quantification of BrdU incorporating cells in the DG four weeks after last BrdU injection and after five weeks of EE. Tcf4Het EE mice have an increased number of BrdU + cells in DG. Scale bar, $100 \mu \mathrm{m} ; \mathrm{n}=5$. c Representative images and quantification of the number of BrdU + single, BrdU + DCX + PROX $1+$ triple and BrdU + PROX1 + double positive cells four weeks after last BrdU injection and after five weeks of EE. The number of immature neurons $($ BrdU + DCX + PROX $1+$ triple positive) is decreased in Tcf4Het EE animals, whereas the number of mature neurons (BrdU + PROX $1+$ positive) is increased. Scale bar, $50 \mu \mathrm{m} ; \mathrm{n}=5$. Data are presented as mean $\pm \mathrm{SEM}$

neurons in Tcf4Het mice less frequently displayed a mature marker profile, which suggests the possibility that
Tcf4 haploinsufficiency impaired maturation and thereby decreased survival of adult-born neurons. 
How TCF4 regulates maturation of neurons on the molecular level remains to be determined. E-box proteins such as TCF4, TCF3 and TCF12 function as transcription factors as homodimers or through formation of heterodimers with bHLH class II transcription factors such as the proneural transcription factors Neurog1 and 2 and the transcription factors of the NeuroD family [1]. NeuroD1 and NeuroD2 have been implied in the maturation of adult-born hippocampal neurons $[43,44]$ and it will be interesting to test whether their interaction with TCF4 is required for dentate granule neuron maturation.

Given our primary goal to gain first insight how Tcf4 haploinsufficiency, which has been causally linked to neurodevelopmental disorders such as Pitt-Hopkins Syndrome and intellectual disability, affects adult neurogenesis, we analysed constitutive heterozygote $T c f 4$ knockout mice. TCF4 is broadly expressed and is critical for the development of a number of neural and non-neural cell types $[18,45-48]$. It therefore remains to be determined how decreased TCF4 dosage in different cell populations contributes to the impairment in adult hippocampal neurogenesis.

We made the interesting observation that long-term exposure to an enriched environment substantially increased the generation of new neurons with a mature marker profile, indicating that behavioural modifications and environmental stimulation may ameliorate TCF4 dosage-dependent defects. Exposure to an enriched environment promotes hippocampal network activity and stimulates adult-born neuron survival and maturation $[35,49]$. Interestingly, recent work demonstrated that the function of TCF4 is neuronal activity dependent $[18,50,51]$ raising the intriguing possibility that enriched environment ameliorated hippocampal neurogenesis deficits through modulation of TCF4 activity. Previous studies showed that TCF4 dosage affects hippocampus-dependent behaviour [23, 51]. It will be interesting to determine whether deficits in adult neurogenesis contribute to hippocampal dysfunction in Tcf4 haploinsufficient mice and whether behavioural modifications such as enriched environment can ameliorate Tcf4 haploinsufficiency associated hippocampus-dependent cognitive deficits in adult mice.

\section{Conclusion}

Our findings suggest that in rodents Tcf4 haploinsufficiency may have a continuous negative impact on hippocampal function by perturbing the physiological formation of new neurons in the adult dentate gyrus. Moreover, our findings raise the interesting possibility that behavioural interventions may allow to ameliorate a subset of Tcf4 haploinsufficiency associated neural deficits during adulthood.

\section{Methods}

\section{Animals and Ethics Statement}

All animal experiments were conducted in accordance with the European Communities Council Directive (86/609/EEC) and received ethical approval by the committee for Animal Research of the Bavarian State authorities. The generation of the knockout allele has been described previously [13]. All animals-except for the animals in the enriched environment experimentswere housed in standard cages (size: $37 \times 21 \times 15 \mathrm{~cm}$ ) with 3-4 mice per cage under a $12 \mathrm{~h}$ light/dark cycle with unlimited access to water and standard rodent food. Mice were housed in the animal facilities of the Helmholtz Center Munich and the Friedrich-Alexander-Universität Erlangen. Animal care was in accordance with institutional guidelines.

Genotyping of the mice was done using PCR and the following primers:

Tcf4Hetfwd MutTCG TGG TAT CGT TAT GCG CC. fwd WTCCG ATG ACA GTG ATG ATG GT. revAAG TTA AGC TGA AGT AAA TAC CCA CA. lacZ fwdATC ACG ACG CGC TGT ATC. lacZ revACA TCG GGC AAA TAA TAT CG.

\section{BrdU injections and Enriched environment}

At the age of eight weeks intraperitoneal 5-bromo-2'deoxyuridine (BrdU) injections were performed twice a day on three consecutive days $(0.1 \mathrm{mg} \mathrm{BrdU/g}$ body weight, per dose). Animals were sacrificed either three hours ( 6 control and 6 haploinsufficient mice) after last injection or after additional four weeks ( 9 control and 5 haploinsufficient mice).

An additional cohort of eight week old Tcf4 haploinsufficient mice (5 animals) was placed in an enriched environment (EE cage size: $60 \times 26 \times 33 \mathrm{~cm}$, containing running wheels, toys, tunnels and nest materials). Mice were injected twice intraperitoneal with BrdU on three consecutive days ( $0.1 \mathrm{mg} \mathrm{BrdU} / \mathrm{g}$ body weight, per dose). Animals were sacrificed four weeks after the last injection.

\section{Tissue preparation}

Mice were killed using $\mathrm{CO}_{2}$ and perfused transcardially with PBS for $5 \mathrm{~min}(20 \mathrm{ml} / \mathrm{min})$, followed by fixation with $4 \%$ paraformaldehyde (PFA) in $0.1 \mathrm{M}$ phosphate buffer (PB), $\mathrm{pH} \mathrm{7.4,} \mathrm{for} 5 \mathrm{~min}$. Brains were postfixed overnight in $4 \%$ PFA at $4{ }^{\circ} \mathrm{C}$, followed by dehydration 
in $30 \%$ sucrose in $0.1 \mathrm{M} \mathrm{PBS}$ at $4{ }^{\circ} \mathrm{C}$. Brains were cut coronally at $40 \mu \mathrm{m}$, using a sliding microtome. Sections were stored at $-20^{\circ} \mathrm{C}$.

\section{Immunohistochemistry}

Free-floating sections were rinsed six times for $10 \mathrm{~min}$ in Tris-buffered saline (TBS: $1 \mathrm{M}$ Tris-HCL, $\mathrm{pH}$ 7.5/0.9\% $\mathrm{NaCl}$ ), and incubated for $72 \mathrm{~h}$ at $4{ }^{\circ} \mathrm{C}$ with primary antibodies (Table 1) in blocking solution, containing $0.25 \%$ Triton X-100 and 3\% donkey serum in TBS. Sections were rinsed in TBS six times for $10 \mathrm{~min}$, incubated overnight at $4{ }^{\circ} \mathrm{C}$ with fluorochrome-labelled secondary antibodies (Table 2) diluted in blocking solution, and rinsed in TBS three times for $10 \mathrm{~min}$. Nuclei were counterstained with DAPI (1:10,000 in 1xTBS) for $10 \mathrm{~min}$, followed by three rinses in TBS for $10 \mathrm{~min}$. Sections were mounted on slides and covered with Aqua-Poly/Mount (Polysciences).

For BrdU stainings, slices were first stained for all antigens of interest except for BrdU. Slices were then postfixed in $4 \%$ PFA for $10 \mathrm{~min}$ at room temperature. Sections were rinsed three times in TBS, incubated in $2 \mathrm{~N} \mathrm{HCl}$ for $10 \mathrm{~min}$ at $37{ }^{\circ} \mathrm{C}$. After two rinses in $0.1 \mathrm{M}$ borate buffer, sections were washed three times with PBS. Detection of BrdU immunoreactivity was conducted as described above.

\section{Imaging and quantification}

For volume, BrdU, and MCM2 quantification, fluorescence signal was detected with an AF6000 Modular
Systems Leica fluorescent microscope and documented with a SPOT-CCD camera and the Leica software LAS AF (Version 2.6.0.7266; Leica Microsystems, Wetzlar Germany). For co-localization analyses, fluorescence signal was detected using a Zeiss LSM 780 confocal microscope with four lasers (405, 488, 550, and $633 \mathrm{~nm}$ ) and $\times 25$ and $\times 40$ objective lens. Images were processed using ImageJ.

For each animal, a series of every 12th section of the dentate gyrus was selected. Volume measurements were performed with ImageJ by tracing the granular zone of dentate gyrus. For BrdU and MCM2 quantification, cells in the granule cell layer and contiguous subgranular zone were counted (52). For co-localization analyses, all $\mathrm{BrdU}+$ cells within the granule cell layer and contiguous subgranular zone in at least one section were analysed for expression of DCX or PROX1. A minimum 50 cells per animal were analysed per marker and animal. Statistical analysis was performed with GraphPad Prism (Graphpad Software Inc.), using unpaired two tailed $t$-test. The data are expressed as mean values \pm SEM. Significant differences were assumed at a level of $p<0.05$.

\section{Antibodies}

See Tables 1 and 2.

Table 1 Primary antibodies

\begin{tabular}{|c|c|c|c|c|c|}
\hline Antigen & Host & Manufacturer & Dilution & Catalog number & RRID \\
\hline BrdU & Rat & Serotec & $1: 500$ & OBT0030CX & AB_609566 \\
\hline DCX & Goat & $\begin{array}{l}\text { Santa Cruz } \\
\text { Biotechnology }\end{array}$ & $1: 500$ & sc-8066 & AB_2088494 \\
\hline CALBINDIN & Mouse & Swant & $1: 300$ & C9638 & AB_2314070 \\
\hline MCM2 & Mouse & BD Bioscience & $1: 500$ & 610,700 & AB_2141952 \\
\hline MCM2 & Rabbit & Cell Signaling Technology & $1: 500$ & 40075 & AB_2142134 \\
\hline NESTIN & Mouse & Millipore & $1: 500$ & MAB353 & AB_94911 \\
\hline PROX1 & Rabbit & Chemicon International & $1: 500$ & AB5475 & AB_177485 \\
\hline TCF4 & Rabbit & Abcam & $1: 500$ & AB130014 & - \\
\hline
\end{tabular}

Table 2 Secondary antibodies

\begin{tabular}{llllll}
\hline Fluorophore & Epitope & Manufacturer & Dilution & Catalog number & RRID \\
\hline Alexa488 & Anti-Goat & Invitrogen & $1: 500$ & A11055 & AB_2534102 \\
Alexa488 & Anti-Rabbit & Invitrogen & $1: 500$ & A21206 & AB_2535792 \\
Cy3 & Anti-Rat & Jackson & $1: 500$ & $712-165-153$ & AB_2340667 \\
Cy3 & Anti-Goat & Jackson & $1: 500$ & $705-165-147$ & AB_2307351 \\
Cy5 & Anti-Mouse & Jackson & $1: 500$ & $715-175-151$ & AB_2340820 \\
Cy5 & Anti-Rabbit & Jackson & $1: 500$ & $711-495-152$ & $A B \_2315775$ \\
\hline
\end{tabular}




\section{Abbreviations}

bHLH: Basic Helix-Loop-Helix; BrdU: 5-Bromo-2'-deoxyuridine; EE: Enriched environment; PFA: Paraformaldehyde; PTHS: Pitt-Hopkins-Syndrome; TCF3: Transcription factor 3; TCF4: Transcription factor 4; TCF12: Transcription factor 12.

\section{Acknowledgements}

We thank all members of the Lie laboratory for helpful discussions and comments on the manuscript.

\section{Authors' contributions}

Conceptualization M-TW, DCL; Investigation, KB, BMH, M-TW; Formal analysis, $\mathrm{KB}, \mathrm{BMH}, \mathrm{M}-\mathrm{TW}, \mathrm{DCL}$; Resources and Funding acquisition, $\mathrm{DCL}$; Writing-Original draft, KB, M-TW, DCL; Writing-Review and Editing, M-TW, DCL; Supervision: $\mathrm{M}-\mathrm{TW}, \mathrm{DCL}$. All authors read and approved the final manuscript.

\section{Authors' information}

The present work was performed in fulfillment of the requirements for obtaining the degree „Dr. med." for K.B..

\section{Funding}

Open Access funding enabled and organized by Projekt DEAL.. This work was supported by Grants from the German Research Foundation (LI 858/6-3 and 9-1 to D.C.L, INST 410/45-1 FUGG), the Bavarian Research Network "ForIPS" and "ForINTER" to D.C.L., the University Hospital Erlangen (IZKF Grants E12, E16, E21 to D.C.L.). K.B. and M.-T.W. are members of the research training group 2162 "Neurodevelopment and Vulnerability of the Central Nervous System" funded by the Deutsche Forschungsgemeinschaft (270949263/ DFG GRK2162/1). The authors declare no competing financial interests.

\section{Availability of data and materials}

The datasets used and/or analysed during the current study are available from the corresponding author on request.

\section{Ethics approval and consent to participate}

All animal experiments were conducted in accordance with the European Communities Council Directive (86/609/EEC) and received ethical approval by the committee for Animal Research of the Bavarian State authorities (55.21-54-2531-80-06). Mice were housed in the animal facilities of the Helmholtz Center Munich and the Friedrich-Alexander-Universität Erlangen. Animal care was in accordance with institutional guidelines.

\section{Consent for publication}

Not applicable.

\section{Competing interests}

The authors declare that they have no competing interests.

Received: 30 July 2020 Accepted: 16 November 2020

Published online: 23 November 2020

\section{References}

1. Bertrand N, Castro DS, Guillemot F. Proneural genes and the specification of neural cell types. Nat Rev Neurosci. 2002;3(7):517-30.

2. Mary L, Piton A, Schaefer E, Mattioli F, Nourisson E, Feger C, et al. Diseasecausing variants in TCF4 are a frequent cause of intellectual disability: lessons from large-scale sequencing approaches in diagnosis. Eur J Hum Genet. 2018;26(7):996-1006.

3. Kharbanda M, Kannike K, Lampe A, Berg J, Timmusk T, Sepp M. Partial deletion of TCF4 in three generation family with non-syndromic intellectual disability, without features of Pitt-Hopkins syndrome. Eur J Med Genet. 2016;59(6-7):310-4.

4. Bedeschi MF, Marangi G, Calvello MR, Ricciardi S, Leone FPC, Baccarin $M$, et al. Impairment of different protein domains causes variable clinical presentation within Pitt-Hopkins syndrome and suggests intragenic molecular syndromology of TCF4. Eur J Med Genet. 2017;60(11):565-71.

5. Zweier C, Peippo MM, Hoyer J, Sousa S, Bottani A, Clayton-Smith J, et al. Haploinsufficiency of TCF4 causes syndromal mental retardation with intermittent hyperventilation (Pitt-Hopkins syndrome). Am J Hum Genet. 2007;80(5):994-1001.

6. Brockschmidt A, Todt U, Ryu S, Hoischen A, Landwehr C, Birnbaum S, et al. Severe mental retardation with breathing abnormalities (Pitt-Hopkins syndrome) is caused by haploinsufficiency of the neuronal bHLH transcription factor TCF4. Hum Mol Genet. 2007;16(12):1488-94.

7. Amiel J, Rio M, de Pontual L, Redon R, Malan V, Boddaert N, et al. Mutations in TCF4, encoding a class I basic helix-loop-helix transcription factor, are responsible for Pitt-Hopkins syndrome, a severe epileptic encephalopathy associated with autonomic dysfunction. Am J Hum Genet. 2007;80(5):988-93.

8. Stefansson H, Ophoff RA, Steinberg S, Andreassen OA, Cichon S, Rujescu $D$, et al. Common variants conferring risk of schizophrenia. Nature. 2009;460(7256):744-7.

9. Steinberg S, de Jong S, Irish Schizophrenia Genomics C, Andreassen OA, Werge T, Borglum AD, et al. Common variants at VRK2 and TCF4 conferring risk of schizophrenia. Hum Mol Genet. 2011;20(20):4076-81.

10. Schizophrenia Psychiatric Genome-Wide Association Study C. Genomewide association study identifies five new schizophrenia loci. Nat Genet. 2011:43(10):969-76

11. De Rubeis S, He X, Goldberg AP, Poultney CS, Samocha K, Cicek AE, et al. Synaptic, transcriptional and chromatin genes disrupted in autism. Nature. 2014;515(7526):209-15.

12. Wang Y, Lu Z, Zhang Y, Cai Y, Yun D, Tang T, et al. Transcription factor 4 safeguards hippocampal dentate gyrus development by regulating neural progenitor migration. Cereb Cortex. 2020;30(5):3102-15.

13. Jung M, Haberle BM, Tschaikowsky T, Wittmann MT, Balta EA, Stadler VC, et al. Analysis of the expression pattern of the schizophrenia-risk and intellectual disability gene TCF4 in the developing and adult brain suggests a role in development and plasticity of cortical and hippocampal neurons. Mol Autism. 2018:9:20.

14. Li H, Zhu Y, Morozov YM, Chen X, Page SC, Rannals MD, et al. Disruption of TCF4 regulatory networks leads to abnormal cortical development and mental disabilities. Mol Psychiatry. 2019;24(8):1235-46.

15. Hill MJ, Killick R, Navarrete K, Maruszak A, McLaughlin GM, Williams BP, et al. Knockdown of the schizophrenia susceptibility gene TCF4 alters gene expression and proliferation of progenitor cells from the developing human neocortex. J Psychiatry Neurosci. 2017;42(3):181-8.

16. Schmidt-Edelkraut U, Daniel G, Hoffmann A, Spengler D. Zac1 regulates cell cycle arrest in neuronal progenitors via Tcf4. Mol Cell Biol. 2014;34(6):1020-30

17. Schoof M, Hellwig M, Harrison L, Holdhof D, Lauffer MC, Niesen J, et al. The basic helix-loop-helix transcription factor TCF4 impacts brain architecture as well as neuronal morphology and differentiation. Eur J Neurosci. 2020;51(11):2219-35.

18. Page SC, Hamersky GR, Gallo RA, Rannals MD, Calcaterra NE, Campbell $M N$, et al. The schizophrenia- and autism-associated gene, transcription factor 4 regulates the columnar distribution of layer $2 / 3$ prefrontal pyramidal neurons in an activity-dependent manner. Mol Psychiatry. 2018;23(2):304-15.

19. Mesman S, Bakker R, Smidt MP. Tcf4 is required for correct brain development during embryogenesis. Mol Cell Neurosci. 2020;106:103502.

20. de Pontual L, Mathieu Y, Golzio C, Rio M, Malan V, Boddaert N, et al. Mutational, functional, and expression studies of the TCF4 gene in Pitt-Hopkins syndrome. Hum Mutat. 2009;30(4):669-76.

21. Rannals MD, Hamersky GR, Page SC, Campbell MN, Briley A, Gallo RA, et al. Psychiatric risk gene transcription factor 4 regulates intrinsic excitability of prefrontal neurons via repression of SCN10a and KCNQ1. Neuron. 2016;90(1):43-55.

22. Brzozka MM, Rossner MJ. Deficits in trace fear memory in a mouse model of the schizophrenia risk gene TCF4. Behav Brain Res. 2013;237:348-56.

23. Brzozka MM, Radyushkin K, Wichert SP, Ehrenreich H, Rossner MJ. Cognitive and sensorimotor gating impairments in transgenic mice overexpressing the schizophrenia susceptibility gene Tcf4 in the brain. Biol Psychiatry. 2010;68(1):33-40.

24. Kempermann G, Gage FH, Aigner L, Song H, Curtis MA, Thuret $S$, et al. Human adult neurogenesis: evidence and remaining questions. Cell Stem Cell. 2018;23(1):25-30.

25. Spalding KL, Bergmann O, Alkass K, Bernard S, Salehpour M, Huttner HB, et al. Dynamics of hippocampal neurogenesis in adult humans. Cell. 2013;153(6):1219-27. 
26. Moreno-Jimenez EP, Flor-Garcia M, Terreros-Roncal J, Rabano A, Cafini F, Pallas-Bazarra N, et al. Adult hippocampal neurogenesis is abundant in neurologically healthy subjects and drops sharply in patients with Alzheimer's disease. Nat Med. 2019;25(4):554-60.

27. Eriksson PS, Perfilieva E, Bjork-Eriksson T, Alborn AM, Nordborg C, Peterson DA, et al. Neurogenesis in the adult human hippocampus. Nat Med. 1998;4(11):1313-7.

28. Sorrells SF, Paredes MF, Cebrian-Silla A, Sandoval K, Qi D, Kelley KW, et al. Human hippocampal neurogenesis drops sharply in children to undetectable levels in adults. Nature. 2018;555(7696):377-81.

29. Toda T, Gage FH. Review: adult neurogenesis contributes to hippocampal plasticity. Cell Tissue Res. 2018;373(3):693-709.

30. Sun Y, Gao Y, Tidei JJ, Shen M, Hoang JT, Wagner DF, et al. Loss of MeCP2 in immature neurons leads to impaired network integration. Hum Mol Genet. 2019;28(2):245-57.

31. Guo W, Allan AM, Zong R, Zhang L, Johnson EB, Schaller EG, et al. Ablation of Fmrp in adult neural stem cells disrupts hippocampus-dependent learning. Nat Med. 2011;17(5):559-65.

32. Contestabile A, Greco B, Ghezzi D, Tucci V, Benfenati F, Gasparini L. Lithium rescues synaptic plasticity and memory in Down syndrome mice. J Clin Investig. 2013;123(1):348-61.

33. LiY, Shen M, Stockton ME, Zhao X. Hippocampal deficits in neurodevelopmental disorders. Neurobiol Learn Mem. 2019;165:106945.

34. van Praag H, Kempermann G, Gage FH. Neural consequences of environmental enrichment. Nat Rev Neurosci. 2000;1(3):191-8.

35. van Praag H, Kempermann G, Gage FH. Running increases cell proliferation and neurogenesis in the adult mouse dentate gyrus. Nat Neurosci. 1999;2(3):266-70.

36. Kempermann G, Kuhn HG, Gage FH. More hippocampal neurons in adult mice living in an enriched environment. Nature. 1997;386(6624):493-5.

37. Fischer B, Azim K, Hurtado-Chong A, Ramelli S, Fernandez M, Raineteau O. E-proteins orchestrate the progression of neural stem cell differentiation in the postnatal forebrain. Neural Dev. 2014;9:23.

38. Tashiro A, Sandler VM, Toni N, Zhao C, Gage FH. NMDA-receptor-mediated, cell-specific integration of new neurons in adult dentate gyrus. Nature. 2006:442(7105):929-33.

39. Jagasia R, Steib K, Englberger E, Herold S, Faus-Kessler T, Saxe M, et al. GABA-CAMP response element-binding protein signaling regulates maturation and survival of newly generated neurons in the adult hippocampus. J Neurosci. 2009;29(25):7966-77.

40. McAvoy KM, Scobie KN, Berger S, Russo C, Guo N, Decharatanachart P, et al. Modulating neuronal competition dynamics in the dentate gyrus to rejuvenate aging memory circuits. Neuron. 2016;91(6):1356-73.

41. Arai Y, Kojima T, Takayama M, Hirose N. The metabolic syndrome, IGF-1, and insulin action. Mol Cell Endocrinol. 2009;299(1):124-8.
42. Crux S, Herms J, Dorostkar MM. Tcf4 regulates dendritic spine density and morphology in the adult brain. PLoS ONE. 2018;13(6):e0199359.

43. Roybon L, Deierborg T, Brundin P, Li JY. Involvement of Ngn2, Tbr and NeuroD proteins during postnatal olfactory bulb neurogenesis. Eur J Neurosci. 2009;29(2):232-43.

44. Gao Z, Ure K, Ables JL, Lagace DC, Nave KA, Goebbels S, et al. Neurod1 is essential for the survival and maturation of adult-born neurons. Nat Neurosci. 2009;12(9):1090-2.

45. Wedel M, Frob F, Elsesser O, Wittmann MT, Lie DC, Reis A, et al. Transcription factor Tcf4 is the preferred heterodimerization partner for Olig2 in oligodendrocytes and required for differentiation. Nucleic Acids Res. 2020:48(9):4839-57.

46. Phan BN, Bohlen JF, Davis BA, Ye Z, Chen HY, Mayfield B, et al. A myelinrelated transcriptomic profile is shared by Pitt-Hopkins syndrome models and human autism spectrum disorder. Nat Neurosci. 2020;23(3):375-85.

47. Ghosh HS, Cisse B, Bunin A, Lewis KL, Reizis B. Continuous expression of the transcription factor e2-2 maintains the cell fate of mature plasmacytoid dendritic cells. Immunity. 2010;33(6):905-16.

48. Flora A, Garcia JJ, Thaller C, Zoghbi HY. The E-protein Tcf4 interacts with Math1 to regulate differentiation of a specific subset of neuronal progenitors. Proc Natl Acad Sci USA. 2007;104(39):15382-7.

49. Tashiro A, Makino H, Gage FH. Experience-specific functional modification of the dentate gyrus through adult neurogenesis: a critical period during an immature stage. J Neurosci. 2007;27(12):3252-9.

50. Sepp M, Vihma H, Nurm K, Urb M, Page SC, Roots K, et al. The intellectual disability and schizophrenia associated transcription factor tcf4 is regulated by neuronal activity and protein kinase A. J Neurosci. 2017;37(43):10516-27.

51. Kennedy AJ, Rahn EJ, Paulukaitis BS, Savell KE, Kordasiewicz HB, Wang J, et al. Tcf4 Regulates Synaptic Plasticity, DNA Methylation, and Memory Function. Cell reports. 2016;16(10):2666-85.

52. Brown JP, Couillard-Despres S, Cooper-Kuhn CM, Winkler J, Aigner L, Kuhn HG. Transient expression of doublecortin during adult neurogenesis. J Comp Neurol. 2003;467(1):1-10

\section{Publisher's Note}

Springer Nature remains neutral with regard to jurisdictional claims in published maps and institutional affiliations.
Ready to submit your research? Choose BMC and benefit from:

- fast, convenient online submission

- thorough peer review by experienced researchers in your field

- rapid publication on acceptance

- support for research data, including large and complex data types

- gold Open Access which fosters wider collaboration and increased citations

- maximum visibility for your research: over $100 \mathrm{M}$ website views per year

At BMC, research is always in progress.

Learn more biomedcentral.com/submissions 